\title{
Impacts of Captioned Movies on Listening Comprehension
}

\author{
Abusaied Janfaza \\ Department of Foreign Languages, Bandar Abbas Branch \\ Islamic Azad University, Bandar Abbas Iran \\ E-mail: s_janfaza@hotmail.com \\ Saghar Javidi Jelyani \\ Department of Language and Literature , Larestan Branch \\ Islamic Azad University, Larestan, Iran \\ E-mail: javidi_s2012@yahoo.com \\ Afshin Soori \\ Department of Language and Literature, Larestan Branch \\ Islamic Azad University, Larestan, Iran \\ E-mail: Afshin_soori@yahoo.com
}

Received: 18-02- 2013

doi:10.7575/aiac.ijels.v.2n.2p.80
Accepted: 01-04-2013

URL: http://dx.doi.org/10.7575/aiac.ijels.v.2n.2p.80

Published: 30-04-2014

\begin{abstract}
With the advent of technology, the implication of authentic multimedia-based teaching materials are using widely in language classrooms. Technology can be in service of teaching different skills such as listening, reading, speaking and writing. Among these skills listening comprehension is a skill in which the learners have problems to master. Regarding this issue, utilizing captions for the education purposes has been a good motivation for conducting some research on the effects of captions of listening skills. However, it seems that there is a gap in the literature whether to use captioned movies in the classroom and whether they are effective in improving listening comprehension. Many studies have been conducted on this issue. However, their findings are conclusive. While some studies refer to the effectiveness of using captions, others revel that they are not so effective for improving the learner's language skills. Hence, the present study is a review of the effects of captioned movies on the improvement of listening skill. In this case, the findings of this study can clarify the role of using captioned movies in improving the listening skill
\end{abstract}

Keywords: captioned movie, technology, listening comprehension, instruction

\section{Introduction}

Learning a foreign language is a very difficult issue in the world of education, and language learners are usually complaining about it. All language skills are difficult for language learners to learn. However, mastering the listening skill is like a dream for majority of language learners. Since listening is a skill which is in the control of the speaker (Brown, 2001; Graham, 2006; Vogely, 1998 as cited in Leveridge \& Yang, 2014), the researchers are always looking for ways to assist learners to learning listening skill. "Caption is described as visual text delivered via multimedia that matches the target language auditory signal verbatim” (Chen, 2011; Stewart \& Pertusa, 2004 as cited in Leveridge \& Yang, 2014, p.545).

Due to its many affordances, the use of multimedia as an instructional medium has become increasingly prevalent in foreign and second language (L2) classroom settings (Leveridge \& Yang, 2012; Sun \& Dong, 2004 as cited in Leveridge and Yang, 2014). It is especially true in the realm of L2 listening comprehension instruction. The integration of multimedia in classrooms provides L2 instructors with different methods of presenting and supporting authentic L2 listening material (Vandergrift, 2007). On one hand, research investigating the use of captioning for L2 listening comprehension has indicated various potential benefits. One of these benefits refers to use of captions to facilitate the learning of second language content (Robin 2007; Stewart \& Pertusa 2004). Moreover, it can improve the vocabulary acquisition (Chai \& Erlam 2008). On the other hand, research has also pointed out pitfalls associated with captioning support such (Vandergrift, 2004 as cited in Leveridge \& Yang, 2014); the impedance of schema building (Diao, Chandler, \& Sweller, 2007); and their lack of compensation for more difficult vocabulary levels and high rates of speech (Danan, 2004). While inconsistencies in research findings exist, the majority of studies agree that at some point, as learners progress, captioning support must eventually be eliminated as this support is not generally transferable to authentic L2 listening environments (Leveridge \& Yang, 2012; Vandergrift, 2004).

Despite the extensive use of captioning as a tool to support and facilitate L2 listening comprehension, one of the major drawbacks is that learners may become reliant on the support (Vandergrift, 2004). A study by Leveridge and Yang 
(2012), which found wide variances in learners' perceptions of captioning, addressed the issue of reliance by proposing a framework designed for the timely elimination of captioning, thus avoiding learner dependence. However, learner affective states, subsequent the removal of captioning support, is an area that has eluded empirical investigation. Moreover, captioning support, as previously mentioned, is prevalent in L2 listening comprehension instruction, thus, learners already reliant, may become frustrated, irritated, or upset, resulting from the removal of this support. These affective states may negatively impact learners' motivation, and willingness to continue learning. Accordingly, the current study aims to satisfy this research gap by examining learners' perceptions concerning the removal of captioning support in L2 listening comprehension and the ensuing affective states.

According to Hsu (1994), the most useful auxiliary for watching videos are captions. The findings of some studies have revealed that when the students want to learn a second or foreign language, they need to receive a great quantity of comprehensible input to achieve the objectives of language learning. Sometimes the students who watch movies in a foreign language can't understand what they have heard because the connection of foreign and its meanings are limited. Consequently, the effectiveness of listening comprehension will be enhanced by using captions and subtitles. Markham, Peter, and McCarthy (2001) defined subtitles as 'the on-screen text in the students' native language combined with a second language soundtrack in the video, while captions are the onscreen text in the original language combined with a soundtrack in the same language" (p.29).

\subsection{The Importance of Captioned Movies}

As the recent accessibility of the authentic videos, a large number of foreign language classes in all over the world are using captioned movies. Regarding this issue, many universities are implementing captioned videos for their language learning courses (Blake, 2005; Chenoweth \& Murday, 2003; Chenoweth, Ushida, \& Murday, 2006; Sanders, 2005; Scida \& Saury, 2006 as cited in Winke, Sydorenko \& Tety, 2010). These types of classes have incorporated captioned videos for teaching a second language. Captioned movies are used for teaching Arabic and Chinese, because they lack adequate qualified teachers (Dahbi, 2004; Freedman, 2004).

To Garza (1991), as caption can assist learners to connect auditory to visual input, and make a connection between form and meaning can be considered as a bonus for foreign language acquisition (Doughty, 2004) . In fact, by the help captions of word boundaries can be identified better. In this case, a main question is what the learners do with captions. However, the unknown point is related to the ability of the teachers to simplify captions for certain learners

\subsection{Theoretical Background}

According to Mayer's (2001 as cited in Leveridge \& Yang, 2013) dual channel, limited capacity, and active prcessing in cognitive theory of multimedia learning support the implementation of captioned movies in language classrooms. AlShehri and Gitsaki (2010) believe that "the active processing premise signifies that one will select the most relevant information as input during information processing, and subsequently integrate the information with prior knowledge" (p.165). In conclusion, by making use of auditory and visual stimuli learning can take place. To this end, captions can support learners collect who the information through the auditory channel and the learners "may reach a point where the audio stimuli cannot be processed quickly enough, resulting in the captions becoming the most understood and relevant stimuli, and thus the preferred stimuli" (Diao et al., 2007, as cited in Leveridge \& Yang, 2013, p. 245)

To Leveridge and Yang (2013) in comparison with visual stimuli, an auditory stimulus makes listening comprehension a more demanding ability. In contrast, learners are allowed to visualize what they hear through the use of captions which is supported by multimedia instruction (Danan, 2004). This ability will remain for long time, and it also allow more time for processing. However, some main questions posed by Winke, Gass, and Sydorenko, (2010 as cited in Leveridge \& Yang, 2013) have been remained unanswered,

Recognizing the importance of background knowledge, Ausubel (1960) first advocated the introduction of relevant concepts used as advance organizers to enhance comprehension and retention of language materials. Ausubel defined the advance organizers as "introductory materials at a higher level of abstraction, generality, and inclusiveness than the learning material itself” (p.268). The claim that advance orga,", nnnnizers can assist learners activate background knowledge, which facilitates comprehension and retention of L2 texts, has been well-documented in L2 research on listening comprehension (Berne, 1995; Chung, 1999, 2002; Chung \& Huang, 1998; Herron, 1994; Herron, Hanley, \& Cole, 1995; Herron, York, Cole, \& Linden, 1998; Li, 2009; Teichert, 1996; Wilberschied \& Berman, 2004 as cited in Leveridge\& Yang, 2013).

\subsection{Definition and Concept of Captioning}

To Vandergrift (2007), "captions may be defined as redundant text that matches spoken audio signals and appears in the same language as the target audio" (p.79). Captions and subtitles are not the same Captioning emerged in foreign language classrooms in the 1980 s as a method of supporting listening comprehension that: increased learners' attention, reduced anxiety, increased motivation, and provided students with immediate verification of what was heard (Froehlich, 1988). A large number of studies (e.g., Leveridge \& Yang, 2012; Vandergrift, 2007) have pointed out the role of multimedia in helping the implementation of captions. Some researchers (e.g. Garza, 1991; Hwang, 2004; Markham, 2000-2001; Robin, 2007; Stewart \& Pertusa, 2004 as cited in Leveridge \& Yang, 2013) believe that understanding of the second language content can be easier by the implication of captions. Moreover, studies indicated that learners held positive attitudes toward captions (Froehlich, 1988). However, how the removal of captioning support affected the learners, was still in vague in these studies. 
In the late 1990's Guillory (1999) investigated the effects of different modes (audio only, keyword captions, and full captions), of captioning on learners' comprehension, and the study indicated that full captioning was significantly beneficial. This finding created a rationale for the use of captions. Learners became accustomed and tended to rely on captions, experiencing negative affective states when the captions were unavailable. More recently, studies have focused on how captions benefit learners at various levels of proficiency (Winke, Gass, Sydorenko, 2010).

\section{Review of Related Studies}

The implication of captions and subtitles in foreign language instruction refers to about forty years ago. The findings of numerous studies (e.g. Borras \& Lafayette, 1994; Danan, 2004; Garza, 1991; Markham \& Peter, 2003 as cited in Leveridge \& Yang, 2013) have revealed that the combination of captions with audio-visual materials was a very effective instructional method which increased both listening and reading comprehension abilities. In fact, learners are able to confirm the information they hear by the captions (Froehlich, 1988; Grimmer, 1992; Vanderplank, 1988). In other words, it can be said that the foreign language information that the learners hear in the video can be visualized by captions (Danan, 2004). To Bird and Williams (2002), captions and subtitles can increase language comprehension. There are some other studies which have revealed that videos with captions can make the vocabulary acquisition easier (Danan, 1992; Hsu, 1994; Markham \& McCarthy, 2001).

According to Vandergrift (2007), when learners are provided with subtitles, they can obstruct their familiarity with pronunciation. Among many different methods for teaching listening by using videos, Liou (2000) found that a large number of students were able to use foreign language captions as auxiliary support. Other strategies that the learners resort to are replay function, and the assistance of native subtitles (Vandergrift, 2007).

In his study, Taylor (2005) investigated the attitudes of the two groups of the students (14 lower level students of the first- year and 71 advanced-level of the third -year) towards using captions. The results of the study indicated that about $35 \%$ of the first-year and about $11 \%$ of the third-year students had negative attitudes toward using captions. They believed that captions distracted and confused them. However, most students in these two levels had positive attitudes towards captions. They believed that captions were. However, "similar to Hayati and Mohmedi's study (2011), the learners' prior experience with captioning support was not indicated, again raising questions regarding extraneous influences such as the previously mentioned novelty effect" (Leveridge \& Yang, 2014, p. 548).

Leveridge and Yang (2014) made a testing instrument which was called caption reliance test (CRT). This instrument could assess the learners' attention "by uncovering what the learner was focusing more heavily on to gain comprehension: audio or textual information" (p. 548). The testing method contained auditory multiple-choice questions and listening exercises. "To uncover the learners' focus, incongruences between the audio and captioning were introduced in the listening exercises. "The multiple-choice questions included one answer that matched the audio and one answer that matched the incongruent caption." (Leveridge \& Yang, 2014, p. 548).

It seems that the findings of numerous studies conducted on the role of captioning are inconsistent. To Vendergrift (2004 as cited in Leveridge \& Yang, 2014) "captioning support is generally not available in authentic, real-time listening” (p.548). In fact, language instruction should improve the learners' second language ability. In this case, learners can communicate without learning support. The more the learners progress, the less teachers try to support learners with captions. Lepper et al., (2005 as cited in Leveridge \& Yang, 2014) state that the teachers are sometimes not sure whether to retain or remove captions during listening comprehension activities. In this case, they provide the learners with information and help the learners to make a correct decision. However, learners may make mistakes in their reliance on learning supports. Seemingly, other researchers (e.g. Hayati \& Mohmedi 2011) have referred to this dilemma that using subtitles are beneficial for L2 language learners.

A large number of studies have been conducted in the area of the implementation of captions for educational purposes especially for learning a foreign language. One informative study has been done by Markham (2005) on how the captions can influence language learning. The author of the study liked to identify whether content of the video can be an effective factor for the usefulness of captions. The findings of the study revealed that the learners could comprehend the videos better when they were supported by captions and background knowledge. In another study, Grgurović \& Hegelheimer (2007 as cited in Winke et al., 2010) the impacts of captions in a multimedia video environment was studied. Regarding the finding of this study, captions were used for longer period of time in comparison to those who transcripts. In another study, Pujola (2002) investigated the strategies of those ESL students who used Web-based multimedia videos (Winke et al., 2010). In fact, she would like to know whether the captions or transcripts are used more by the students while they are watching videos. The findings of this study indicated that, those students had problems in listening skills tried to take advantage of captions and transcripts more to comprehend better. In addition, the results showed that all students had better experiences with captions. In fact, students believed that under the effect of using captions they could improve their listening skills (Chen, 2011). To Pujola (2002 as cited in Chen 2011), some learners misused captions for listening comprehension. To this end, "this misuse of captions can potentially inhibit the development of listening strategies, and explained that students needed to be advised when they were using captions" ( p. 252).

As a final remark, since caption videos are accessible, easy to make, using captioned videos for learning a foreign language has become common. Today, captions are considered as pedagogical tools and language acquisition is supported by the implications of captions in learning areas. Captions can also assist the learners to integrate the written 
and aural information (Winke et al., 2010). To identify the multiple functions of captions, and to what degree captions can be used by different proficiency level learners, further studies should be carried out.

\section{Reflection}

Regarding the findings of the studies reviewed in previous parts, it is very difficult to make a correct judgment on the effectiveness of the captions for some reasons. First, the majority of the previous studies had some flaws in their designs or conceptual frameworks. In addition, those studies took advantage of different instruments (e.g. listening, reading, or vocabulary test) to evaluate the impacts of captions (Winke et al., 2010). To this end, it seems that caption is still an unknown issue and it needs further studies to clarify its different aspects. To Etemadi (2012), the impacts of captions on the acquisition of some language like Russian, Chinese, and Arabic have not been considered. And finally, a pedagogical question is related to the appropriate time for the learners to be exposed to captions. To Winke et al., (2010), the results of the study by Pujola (2002) indicate that captions are useful and can be overused. To avoid overuse of captions, it is suggested that the videos be broadcasted once with captions and once without captions.

There is a gap in the literature whether to use captioned movies in the classroom and whether they are effective in improving the listening comprehension. However, the findings of the previous studies are not conclusive. While some researchers (e.g. Danan, 2004; Hayati \& Mohmedi, 2011) believed that captions can act as supporters for improving the lerners' comprehension. Some other researchers (e.g. Stewart \& Pertusa, 2004; Vandergrift, 2004; 2007) considered captions as hindrance or distracting (Taylor, 2005 as cited in Leveridge \& Yang, 2014). In addition, both Vandergrift (2004) and Yanagawa and Green (2008) pointed out that the use of captioning might also delay learners' advancement of their listening ability, rendering them and make them unable to comprehend the second language (L2) in real-life situations where captions are not readily available (Leveridge \& Yang, 2014).

\section{References}

Ausubel, D. P. (1960). The use of advance organizers in the learning and retention of meaningful verbal material. Journal of Educational Psychology, 51, 267-272.

Berne, J. E. (1995). How does varying pre-listening activities affect second language listening comprehension? Hispania, 78, 316-329.

Chung, J. M. (1999). The effects of using video texts supported with advance organizers and captions on Chinese college students' listening comprehension: An empirical study. Foreign Language Annals, 32, 295-308.

Chung, J. M., \& Huang, S. C. (1998). The effects of three aural advance organizers for video viewing in a foreign language classroom. System, 26, 553-565.

Danan, M. (2004). Captioning and subtitling: Undervalued language learning strategies. Meta, 49(1), 67-77.

Diao, Y., Chandler, P. \& Sweller, J. (2007). The effect of written text on comprehension of spoken English as a foreign language. American Journal of Psychology, 120(2), 237-261.

Froehlich, J. (1988). German videos with German subtitles: A new approach to listening comprehension development. Die Unterrichtspraxis/Teaching German, 21(2), 199-203.

Garza, T. (1991) Evaluating the use of captioned video materials in advanced foreign language learning. Foreign Language Annals, 24(3): 239-258.

Goodwin-Jones, R. (2007) Digital video update: YouTube, Flash, High-Definition. Language Learning \& Technology, 11(1): 16-21.

Grgurovic, M. \& Hegelheimer, V. (2007) Help options and multimedia listening: students' use of subtitles and the transcript. Language Learning and Technology, 11(1), 45-66.

Guillory, H. G. (1999). The effect of keyword captions to authentic French video on learner comprehension. CALICO Journal, 15(1-3), 89-108.

Hanley, J. E. B., Herron, C. A. \& Cole, S. P. (1995). A Comparison Study of Two Advance Organizers for Introducing Beginning Foreign Language Students to Video. The Modern Language Journal, 79, 387-396.

Hayati, A. and Mohmedi, F. (2011) The effect of films with and without subtitles on listening comprehension of EFL learners. British Journal of Educational Technology, 42(1): 181-192.

Herron, C. A. (1994). An investigation of the effectiveness of using an advance organizer to introduce video in the foreign language classroom. The Modern Language Journal, 78, 190-198.

Hwang, Y. L. (2004) The effect of the use of videos captioning on English as a foreign language on college students' language learning in Taiwan (Unpublished doctoral dissertation). Ann, Arbor MI: UMI.

Krashen, S. (1981). Second Language Acquisition and Second Language Learning, Pergamon Press, New York, 1981.

Krashen, S. (1985). Inquiries \& Insights. Second Language Teaching: Immersion and Bilingual Education, Literacy, Alemany Press, Hayward, California

Lepper, M. R., Corpus, J. H. and Iyengar, S. S. (2005) Intrinsic and extrinsic motivational orientations in the classroom: Age differences and academic correlates. Journal of Educational Psychology, 97(2): 184-196. 
Leveridge, A. N. \& Yang, J. C. (2012). Effect of Medium: A Conceptual Framework for the removal of Supporting Captions for EFL Listening Comprehension in Multimedia Instructional Delivery. Proceedings from the: 15th International CALL Research Conference. Taichung, Taiwan.

Leveridge, A. N., \& Yang, J. C. (2013). Testing learner reliance on caption supports in second language listening comprehension multimedia environments. ReCALL, 25(2), 199-214.

Leveridge, A. N., \& Yang, J. C. (2014). Learner perceptions of reliance on captions in EFL multimedia listening comprehension. Computer Assisted Language Learning, 27(6), 545-559.

Li, C. H. (2009). The use of advance organizers to prepare college students to listen in the foreign language classroom. Taiwan Journal of TESOL, 6(1), 83-110.

Markham, P. L. et al. (2001). The effects of native language vs. target language captions on foreign language students' DVD video comprehension. Foreign Language Annals, 34 (5), 439-445.

Mayer, R. E. (2001) Multimedia learning. New York: Cambridge University Press.

Pujola' , J. T. (2002) CALLing for help: Researching language learning strategies using help facilities in a web-based multimedia program. ReCALL, 14(2): 235-262.

Robin, R. (2007). Commentary: learner-based listening and technological authenticity. Language

Learning \& Technology, 11 (1), 109-115.

Smidt, E. \& Hegelheimer, V. (2004). Effects of online academic lectures on ESL listening comprehension, incidental vocabulary acquisition and strategy use. Computer Assisted Language Learning, 17(5), 517-556.

Stewart, M., \& Pertusa, I. (2004). Gains to language learners from viewing target language closed-captioned films. Foreign Language Annals, 37 (3), 438-447.

Sun, Y. \& Dong, Q. (2004). An experiment on supporting children's English vocabulary learning in multimedia context. Computer Assisted Language Learning, 17 (2), 131-147.

Taylor, G. (2005). Perceived processing strategies of students watching captioned video. Foreign Language Annals, 38 (3), 422-427.

Teichert, H. U. (1996). A comparative study using illustration, brainstorming, and questions as advance organizers in intermediate college German conversation classes. The Modern Language Journal, 80, 509-517.

Vandergrift, L. (2007). Recent developments in second and foreign language listening comprehension research. Language Teaching, 40 (3), 191-210.

Wilberschied, L., \& Berman, P. M. (2004). Effect of using photos from authentic video as advance organizers on listening comprehension in an FLES Chinese class. Foreign Language Annals, 37, 534-543.

Winke, P., Gass, S., \& Sydorenko, T. (2010). The effects of captioning videos used for foreign language listening activities. Language Learning \& Technology, 14(1), 65-86. 